\title{
Propagação in vitro e caracterização química do óleo essencial de Lavandula angustifolia cultivada no Sul do Brasil
}

\author{
In vitro propagation and chemical characterization of the essential oil of Lavandula angustifolia \\ cultivated in Southern Brazil
}

\author{
Marília Pereira Machado $^{\mathrm{I}}$ Marlise Nara Ciotta $^{\mathrm{II}}$ Cícero Deschamps $^{\mathrm{I}}$ Flávio Zanette $^{\mathrm{I}}$ \\ Lílian Cristina Côcco ${ }^{\text {III }}$ Luiz Antonio Biasi ${ }^{\mathrm{I}}$
}

\section{RESUMO}

\begin{abstract}
Lavandula angustifolia Mill. é uma importante planta produtora de óleos essenciais, que apresenta dificuldade de propagação pelo enraizamento de estacas, sendo a produção de mudas realizada nesse trabalho pela técnica de micropropagação, em que foram avaliadas algumas condições do cultivo in vitro. As mudas produzidas pela micropropagação foram cultivadas em São Joaquim (SC). O óleo essencial das inflorescências foi extraído por hidrodestilação, e analisado quanto a sua composição por GC/MS, em dois anos de colheita. $O$ meio de cultura LS apresentou melhor resposta no desenvolvimento das brotações, não sendo observadas brotações com necrose apical. Meios de cultura mais diluídos como o $1 / 2$ MS e o WPM, apresentaram altas taxas de hiperidricidade e necrose apical das brotações. A citocinina $B A P$ influenciou a multiplicação das brotações, sendo a qualidade mantida com 1,0 $\mu \mathrm{M}$ ao longo de quatro subcultivos. A sobrevivência das plantas na aclimatização foi de $80 \%$. Os teores de óleo essencial foram de 4,0\% e 5,25\%, na primeira e segunda colheita, respectivamente. Os compostos majoritários foram o linalol $(46,88 \%$ e $37,25 \%)$ e acetato de linalila $(10,09 \%$ e 12,24\%).
\end{abstract}

Palavras-Chave: Lamiaceae, micropropagação, hidrodestilação, compostos voláteis.

\section{ABSTRACT}

Lavandula angustifolia Mill. is an important producer of essential oil, which presents the difficulty of propagation stem cuttings. In this work the propagation of plant was carried out by micropropagation technique, in which certain conditions were evaluated in vitro. The micropropagated plants were grown in São Joaquim (SC). The essential oil of the inflorescences was extracted by hydrodistillation and analyzed for their composition by GC/ $M S$ in two years of harvest. The culture medium LS showed a better response in the development of shoots. Culture media more diluted as the 1/2 MS and WPM showed high rates of hyperhrydricity and apical necrosis. The BAP influenced the shoot multiplication and the quality being maintained with 1.0 $m M$ over four subcultures. The survival in the acclimatization of plants was $80 \%$. The content of essential oil were $4.0 \%$ and $5,25 \%$ in the first and second harvest, respectively. The major compounds were linalool $(46.88 \%$ and $37.25 \%)$ and linalyl acetate $(10.09 \%$ and $12.24 \%)$.

Key word: Lamiaceae, micropropagation, hydrodistillation, volatile compounds.

\section{INTRODUÇÃO}

Lavandula angustifolia Mill. conhecida como lavanda (Lamiaceae) é um arbusto que ocorre em altitude de até $1500 \mathrm{~m}$, sendo encontrada em toda a região do Mediterrâneo. É uma importante espécie medicinal e aromática, utilizada principalmente na extração de óleo essencial, mas também tem sido utilizada como planta ornamental e melífera. Cultivada em várias regiões de clima temperado do mundo todo, seu grande potencial está na produção de óleo essencial (MOON et al., 2006), que pode ser extraído de suas folhas ou flores, sendo empregado nas indústrias

'Departamento de Fitotecnia e Fitossanitarismo, Universidade Federal do Paraná (UFPR), 81531-990, Curitiba, PR, Brasil. Email: ma_rilia10@hotmail.com.*Autor para correspondência.

"Empresa de Pesquisa Agropecuária e Extensão Rural de Santa Catarina (Epagri), São Joaquim, SC, Brasil.

IIIDepartamento de Engenharia Química, UFPR, Curitiba, PR, Brasil. 
cosmética, alimentícia, farmacêutica e de perfumaria (TSURO et al., 2000). O óleo essencial da $\boldsymbol{L}$. angustifolia é composto por mais de 100 componentes, principalmente terpenóides. Os compostos de maior interesse econômico são linalol e acetato de linalila (SUGAWARA et al., 1998).

A propagação de L. angustifolia por sementes é geralmente lenta, além de apresentar variações em diferentes características do genótipo de interesse, como na taxa de crescimento e na composição do óleo essencial (MOUTET, 1980; PANIZZA \& TOGNONI, 1991). Espécies do gênero Lavandula vêm sendo propagadas com sucesso pela micropropagação (FRANBETTI et al., 2009; DIAS et al. 2002; NOGUEIRA \& ROMANO, 2002; ECHEVERRIGARAY etal., 2005).A partir da micropropagação é possível a produção em larga escala de plantas geneticamente idênticas à planta matriz, que é extremamente importante para a propagação de genótipos selecionados e quimiotipos de espécies produtoras de óleos essenciais (ANDRADE et al., 1999). Contudo, são muitos os fatores que estão envolvidos na regeneração das plantas in vitro, entre eles estão o tipo de meio de cultura, seguido do suplemento de reguladores de crescimento, concentração de sacarose, iluminação, tipo de explante, entre outros (ZHANG et al., 2003), sendo necessário encontrar as condições mais adequadas para cada genótipo que se pretende propagar.

A propagação in vitro tem sido aplicada para diversas espécies de Lavandula, na qual a regeneração das plantas é realizada via organogênese direta e indireta utilizando diferentes tipos de explantes e meios de cultura. Estudos preliminares de embriogênese somática foram realizados para $\boldsymbol{L}$. angustifolia por KINTZIOS et al. (2002). Para L. latifolia foram produzidas brotações diretamente dos tecidos dos explantes por CALVO \& SEGURA (1989) e GRAS \& CALVO (1996), e também a partir de calos (CALVO \& SEGURA, 1988; JORDAN et al. 1990), assim como para L. angustifolia (QUAZI, 1980; TSURO et al. 1999) e o híbrido lavandin (PANIZZA \& TOGNONI, 1991). Gemas axilares de plantas adultas foram utilizadas para iniciar o cultivo in vitro de $\boldsymbol{L}$. angustifolia (ANDRADE et al., 1999).

Hiperidricidade é um problema encontrado com frequência na micropropagação das espécies de Lavandula (ANDRADE et al., 1999; TSURO et al., 2000; DIAS et al., 2002). Apresenta-se como uma má formação fisiológica que resulta na hidratação excessiva, baixa lignificação, função estomática prejudicada e reduzida resistência mecânica dos tecidos vegetais provenientes da cultura de tecidos, e como consequência reduz a capacidade de sobrevivência das plantas na aclimatização (KEI-ICHIRO et al., 1998).
Neste contexto, este trabalho teve por objetivo a produção de mudas de L. angustifolia utilizando a técnica de micropropagação e a caracterização química do óleo essencial produzido pelas plantas após o estabelecimento a campo.

\section{MATERIAL E MÉTODOS}

Condições de cultivo in vitro

Todas as culturas in vitro foram mantidas em sala de crescimento, sob luz fluorescente branca fria com densidade de fluxo de fótons de $20 \mu \mathrm{mol} \mathrm{m} \mathrm{m}^{-2} \mathrm{~s}^{-1}$, fotoperíodo de $16 \mathrm{~h}$ e temperatura de $25 \pm 2^{\circ} \mathrm{C}$. Todos os meios de cultura tiveram o $\mathrm{pH}$ ajustado para 5,8 e foram autoclavados durante $20 \mathrm{~min}$ a $120^{\circ} \mathrm{C}$.

Estabelecimento in vitro

Os materiais vegetais utilizados como fontes de explantes foram ápices caulinares de aproximadamente 5,0mm de comprimento, coletados de um único genótipo de $\boldsymbol{L}$. angustifolia $\mathrm{cv}$. 'Provence Blue', cultivado em vaso contendo solo como substrato e mantido em casa de vegetação. Para a desinfestação, os explantes foram lavados em água corrente seguido do tratamento com Cercobin ${ }^{\circledR}(2 \%)$ por $40 \mathrm{~min}$. Em seguida foi realizada imersão em etanol $(70 \%)$ por 20 seg e tratamento com hipoclorito de sódio (1\%) mais Tween- $20^{\circledR}(0,2 \%)$ por $20 \mathrm{~min}$, após quatro lavangens em água deionizada esterilizada.

Os ápices caulinares foram isolados individualmente, em frascos contendo $10 \mathrm{ml}$ de meio de cultura MS (MURASHIGE \& SKOOG 1962) suplementado com $0,5 \mu \mathrm{M}$ de BAP e $6 \mathrm{~g} \mathrm{~L}^{-1}$ de ágar $\left(\operatorname{Vetec}^{\circledR}\right)$.

Efeito de BAP na multiplicação das brotações

Brotações de L. angustifolia cv. 'Provence

Blue' estabelecidas in vitro foram padronizadas com $1,0 \mathrm{~cm}$ de comprimento e um par de folhas e, cultivadas em meio de cultura MS, suplementado com 100 $\mathrm{mg} \mathrm{L}^{-1}$ de mio-inositol, $30 \mathrm{~g} \mathrm{~L}^{-1}$ de sacarose e $6 \mathrm{~g} \mathrm{~L}^{-1}$ de agar. A citocinina 6-benzilaminopurina (BAP) foi adicionada ao meio de cultura em diferentes concentrações $(0,5$; $1,0 ; 2,0$ e 5,0 $\mu \mathrm{M})$. O pH foi ajustado para 5,8 antes da autoclavagem.

Efeito da composição do meio de cultura na multiplicação das brotações

As brotações obtidas a partir do cultivo inicial, padronizadas com $1,0 \mathrm{~cm}$ de comprimento e um par de folhas, foram cultivadas nos diferentes meios de cultura MS, MS/2, LS (LINSMAIER \& SKOOG, 1965) e WPM (LLOYD \& MCCOWN, 1980) suplementados com as vitaminas do meio MS (exceto o meio de cultura 
LS, suplementado somente com $0,4 \mathrm{mg} \mathrm{L}^{-1}$ de tiamina), $100 \mathrm{mg} \mathrm{L}^{-1}$ de mio-inositol, $30 \mathrm{~g} \mathrm{~L}^{-1}$ de sacarose, $1,0 \mu \mathrm{M}$ de BAP e $6 \mathrm{~g} \mathrm{~L}^{-1}$ de ágar $\left(\operatorname{Vetec}^{\oplus}\right)$. Após 40 dias de cultivo, as variáveis analisadas foram altura $(\mathrm{cm})$ das brotações, número de folhas, número de brotações por explante, porcentagem de hiperidricidade e porcentagem de necrose apical. O delineamento experimental foi inteiramente casualizado, com quatro repetições e 10 explantes por parcela. $\mathrm{O}$ experimento foi repetido duas vezes.

\section{Enraizamento e aclimatização}

O enraizamento e aclimatização das plantas foi realizado segundo MACHADO et al. (2011). Na qual microestacas foram seccionadas com $4,0 \mathrm{~cm}$ de comprimento, em seguida tratadas com ácido indolbutírico (AIB) via talco na concentração de $5,0 \mathrm{mM}$. As microestacas foram colocadas em tubetes plásticos de $53 \mathrm{~cm}^{3}$ contendo substrato comercial (Plantmax $\mathrm{HT}^{\circledast}$ ), e mantidas em câmara de nebulização intermitente, controlada por temporizador com intervalo de rega fixo. A programação utilizada para a nebulização foi das 8 às $17 \mathrm{~h}$, com irrigação de $15 \mathrm{~s}$ a cada $15 \mathrm{~min}$; das 17 às $23 \mathrm{~h}$, com irrigação de $15 \mathrm{~s}$ a cada uma hora e; das 23 às $8 \mathrm{~h}$, com irrigação de $15 \mathrm{~s}$ a cada $3 \mathrm{~h}$, por um período de 15 dias. $\mathrm{O}$ bico nebulizador empregado apresenta vazão de $48 \mathrm{~L} \mathrm{~h}^{-1}$. O sombreamento da câmara de nebulização é feito por manta termo-refletora (Aluminet ${ }^{\circledR}$ ). Após este período, as plantas foram transferidas para casa-de-vegetação com irrigação manual com mangueira até a satiração do substrato, realizada diariamente.

Estabelecimento das plantas a campo

Após a aclimatização, as mudas micropropagadas de $\boldsymbol{L}$. angustifolia cv. 'Provence Blue' permaneceram em casa-de-vegetação por um período de seis meses. Em seguida foram levadas para a Estação Experimental da EPAGRI (Empresa de Pesquisa Agropecuária e Extensão Rural de Santa Catarina S.A.), localizada no município de São Joaquim (SC) (S $28^{\circ} 17^{\prime} 39^{\prime \prime}$, W $49^{\circ} 55^{\prime}$ '56" e $1.415 \mathrm{~m}$ de altitude), em janeiro de 2010. O clima da região, segundo a classificação de Köppen, é subtropical com verões brandos (Cfb).

O solo é classificado como Neossolo Litólico Húmico (EMBRAPA, 2006), com cerca de 0,40m de horizonte $\mathrm{A}$, apresentando textura argilo-arenosa com $40 \%$ argila, $50 \%$ areia, $10 \%$ silte, com uma profundidade efetiva de $0,40 \mathrm{~m}$, sendo desenvolvido de riodacitos da formação Serra Geral. As características químicas do solo no início do experimento foram: $\mathrm{P}=44,3 \mathrm{mg} \mathrm{dm}^{-3}$; $\mathrm{K}=0,65 \mathrm{cmol}_{\mathrm{c}} \mathrm{dm}^{-3} ; \mathrm{Ca}=4,3 \mathrm{cmol}_{\mathrm{c}} \mathrm{dm}^{-3} ; \mathrm{Mg}=2,9 \mathrm{cmol}_{\mathrm{c}}$ $\mathrm{dm}^{-3} ; \mathrm{SB}=7,85 \mathrm{cmol}_{\mathrm{c}} \mathrm{dm}^{-3} ; \operatorname{argila}=65 \% ; \mathrm{V}=48 \%$ e $\mathrm{pH}$
$(\mathrm{SMP})=5,4$. Valores determinados pelo Laboratório de Análise de Solos (UFPR).

No plantio as mudas foram dispostas em duas fileiras com espaçamento de $0,70 \mathrm{~m}$ entre plantas e $1,0 \mathrm{~m}$ entre linhas.

As colheitas das inflorescências foram realizadas emjaneirode 2010, noperíodo damanhã. Omaterial vegetal foi conduzido ao Laboratório de Ecofisiologia, do Departamento de Fitotecnia e Fitossanitarismo (UFPR), Curitiba (PR), onde foi realizada a destilação do óleo essencial a partir das inflorescências frescas.

Extração e análise do óleo essencial

As extrações de óleo essencial foram realizadas por hidrodestilação em aparelho graduado Clevenger, durante 4 horas. O material vegetal, amostras de $100 \mathrm{~g}$ de inflorescências frescas, foi colocado em balão volumétrico de dois litros e acrescentado um volume de um litro de água destilada. O óleo extraído foi quantificado com micropipeta de precisão (10$100 \mu \mathrm{L})$ e colocado em tubos plásticos de $2 \mathrm{~mL}$, armazenado à $-20^{\circ} \mathrm{C}$ até o momento da análise.

A caracterização química do óleo essencial foi realizada no Laboratório de Análise de Combustíveis Automotivos, do Departamento de Engenharia Química da UFPR, mediante cromatografia em fase gasosa acoplada à espectrometria de massas. $\mathrm{O}$ equipamento e as condições operacionais utilizadas para a quantificação dos constituintes do óleo essencial foram o cromatógrafo gasoso Varian, modelo CP 3800 com detector FID (CG_FID); coluna capilar Chrompack de sílica fundida CP-SIL 8 CB, 0,25mm de diâmetro interno, $30 \mathrm{~m}$ de comprimento e $0,25 \mu \mathrm{m}$ de filme líquido; temperatura do injetor: $250^{\circ} \mathrm{C}$, split 1:200; quantidade de amostra injetada foi: $1,0 \mu \mathrm{L}$; pressão na coluna: 30,0 psi; gás de arraste: foi o hélio. Gás de make up: ar sintético, nitrogênio e hidrogênio. Temperatura do detector FID: $300^{\circ} \mathrm{C}$. A programação de temperatura do forno: temperatura inicial de $60^{\circ} \mathrm{C}$, elevação de temperatura a $90^{\circ} \mathrm{C}, 140^{\circ} \mathrm{C}$ e $240^{\circ} \mathrm{C}$ por 5 minutos. $\mathrm{O}$ tempo total da corrida foi de 40 minutos.

Os índices de retenção (IR) para o óleo essencial das inflorescências foram calculados após a injeção de uma série homóloga de $n$-alcanos, nas mesmas condições utilizadas para as amostras. $\mathrm{O}$ espectro de massa e o índice de retenção linear foram comparados aos reportados na literatura para identificação segura (ADAMS, 2007).

Análise estatística

Os dados foram submetidos à análise de variância e as médias comparadas pelo teste de Duncan 
a 5\% de probabilidade. Os dados em porcentagem foram transformados em arc sen $\sqrt{\mathrm{x} / 100}$. As análises estatísticas foram realizaram utilizando-se o programa ASSISTAT versão 7.5 (SILVA \& AZEVEDO, 2006).

\section{RESULTADOS E DISCUSSÃO}

Efeito de BAP na multiplicação das brotações

A citocinina BAP tem sido considerada uma das mais efetivas na multiplicação de brotações in vitro. $\mathrm{Na}$ multiplicação de $\boldsymbol{L}$. angustifolia seu efeito, em diferentes concentrações, na altura das brotações ao longo de quatro subcultivos está apresentado na tabela 1 , onde pode ser observado que houve redução da altura das brotações em todas as concentrações de BAP avaliadas no quarto subcultivo. Concentrações mais baixas da citocinina proporcionaram maior altura das brotações ao longo dos quatro subcultivos. $\mathrm{O}$ efeito das citocininas não se restringe a uma subcultura, pois há um efeito residual de uma subcultura para outra (SOARES et al., 2011). Esse efeito pode ser problemático quando afeta o alongamento das brotações.

As concentrações mais elevadas de BAP aplicadas $(2,0$ e $50 \mu \mathrm{M})$ produziram maior número de brotações por explante, a partir do terceiro subcultivo. Ao longo dos subcultivos o número de brotação por explante, nas concentrações de 2,0 e 5,0 $\mu \mathrm{M}$, variou de aproximadamente 1,3 a 4,4 brotações por explante. $\mathrm{Na}$ concentração de $1,0 \mu \mathrm{M}$ de BAP o número de brotações por explante permaneceu inalterado no terceiro e quarto subcultivo, apresentando 2,5 brotações por explante (Tabela 1). Na fase de multiplicação de L. dentata foi observado que os subcultivos reduziram drasticamente o número de brotações produzidas na presença de 2,0 $\mu \mathrm{M}$ de BAP(JORDAN et al., 1998).

Apesar das melhores taxas de multiplicação das brotações terem sido encontradas nas concentrações de 2,0 e 5,0 $\mu \mathrm{M}$ de BAP, as maiores porcentagens de hiperidricidade também foram obtidas nestas concentrações, chegando a $100 \%$ no quarto subcultivo. Diversos trabalhos com lavanda in vitro apresentaram este efeito da citocinina na multiplicação, que a pesar das altas taxas de proliferação das brotações, estas vieram acompanhadas da hiperidricidade (ECHEVERRIGARAY et al., 2005; DIAS et al., 2002; ANDRADE et al., 1999; ZUZARTE, et al., 2010).

Efeito da composição do meio de cultura na multiplicação das brotações

De acordo com os resultados observados, os meios de cultura comparados para a micropropagação de L. angustifolia cv. 'Provence blue' demonstraram efeito significativo para todas as variáveis analisadas, caracterizando que a composição do meio de cultura influencia a morfogênese in vitro dessa espécie, pois os meios de cultura comparados apresentaram diferentes respostas no crescimento e desenvolvimento das brotações. Com relação à altura das brotações, o meio de cultura MS proporcionou melhores resultados, obtendo-se brotações de $2,3 \mathrm{~cm}$ em média. Já para os meios de cultura MS/2 e WPM, os resultados observados foram inferiores $(1,3 \mathrm{~cm}$ e $1,5 \mathrm{~cm}$, respectivamente). Essa redução na altura das brotações pode ter ocorrido devido à menor concentração de $\mathrm{N}$ nos meios MS/2 e WPM (Tabela 2). Os efeitos dos meios de cultura MS/2 e WPM também foram responsáveis pela redução do número de folhas por brotação e o número de brotações por explante, em comparação aos meios de cultura MS e LS (Tabela 2). Para espécies lenhosas, como Aspidosperma polyneuron e Vaccinium ashei, o meio de cultura WPM apresentou resultado positivo na micropropagação dessas espécies (RIBAS et al., 2005; SILVA et al., 2006).

Tabela 1 - Efeito de BAP (6-benzilaminopurina) em diferentes concentrações na altura das brotações de $\boldsymbol{L}$. angustifolia cv. 'Provence Blue', na fase de multiplicação.

\begin{tabular}{|c|c|c|c|c|c|c|c|c|c|c|c|c|}
\hline \multirow[t]{2}{*}{$\mathrm{BAP}(\mu \mathrm{M})$} & \multicolumn{6}{|c|}{----------Subcultivo 1----------- -----------Subcultivo 2-------- } & \multicolumn{3}{|c|}{----------Subcultivo 3--------- } & \multicolumn{3}{|c|}{----------Subcultivo 4-------- } \\
\hline & TMM & $\mathrm{CMB}$ & $\mathrm{PBH}$ & TMM & $\mathrm{CMB}$ & $\mathrm{PBH}$ & TMM & $\mathrm{CMB}$ & PBH & TMM & $\mathrm{CMB}$ & PBH \\
\hline 0,5 & $1,6 \mathrm{a}$ & $1,8 \mathrm{~b}$ & $5 \mathrm{~b}$ & $2,4 \mathrm{a}$ & $1,8 \mathrm{~b}$ & $5 \mathrm{c}$ & $1,8 \mathrm{c}$ & 2,9 a & $5 \mathrm{~b}$ & $1,9 \mathrm{c}$ & $1,4 \mathrm{a}$ & $5 \mathrm{c}$ \\
\hline 1,0 & $1,5 \mathrm{a}$ & $2,3 \mathrm{a}$ & $5 \mathrm{~b}$ & $1,7 \mathrm{~b}$ & $2,9 \mathrm{a}$ & $15 \mathrm{a}$ & $2,5 \mathrm{~b}$ & $2,2 \mathrm{~b}$ & $30 \mathrm{a}$ & $2,5 \mathrm{~b}$ & $1,7 \mathrm{a}$ & $25 \mathrm{~b}$ \\
\hline 2,0 & $1,3 \mathrm{a}$ & $2,1 \mathrm{a}$ & $5 \mathrm{~b}$ & $1,5 \mathrm{~b}$ & $2,1 \mathrm{~b}$ & $10 \mathrm{~b}$ & $3,4 \mathrm{a}$ & $2,3 \mathrm{~b}$ & $30 \mathrm{a}$ & $4,4 \mathrm{a}$ & $1,7 \mathrm{a}$ & $100 \mathrm{a}$ \\
\hline 5,0 & $1,6 \mathrm{a}$ & $1,6 \mathrm{~b}$ & $20 \mathrm{a}$ & $2,3 \mathrm{a}$ & $2,3 \mathrm{~b}$ & $15 \mathrm{a}$ & $3,3 \mathrm{a}$ & $2,1 \mathrm{~b}$ & $30 \mathrm{a}$ & $4,4 \mathrm{a}$ & $1,4 \mathrm{a}$ & $100 \mathrm{a}$ \\
\hline
\end{tabular}

Médias seguidas pela mesma letra na coluna não diferem significativamente pelo teste de Scott-Knott $(\mathrm{p} \leq 0,05)$. TMM = taxa média de multiplicação; $\mathrm{CMB}=$ comprimento médio das brotações; $\mathrm{PBH}=$ porcentagem de brotações hiperídricas. 
Tabela 2 - Efeito de diferentes meios de cultura na micropropagação de L. angustifolia cv. 'Provence Blue', após 40 dias de cultivo.

\begin{tabular}{|c|c|c|c|c|}
\hline Meios de cultura & $\begin{array}{l}\text { Altura das brotações } \\
\qquad(\mathrm{cm})^{1}\end{array}$ & Número de folhas por brotação ${ }^{1}$ & Brotações por explante $^{1}$ & $\begin{array}{l}\text { Hiperidricidade das brotações } \\
(\%)^{1}\end{array}$ \\
\hline MS & $2,3 \pm 0,2 \mathrm{a}$ & $9,4 \pm 1,7 \mathrm{a}$ & $3,3 \pm 0,5 \mathrm{a}$ & $23 \mathrm{a}$ \\
\hline $\mathrm{MS} / 2$ & $1,3 \pm 0,2 \mathrm{~b}$ & $6,4 \pm 0,5 b$ & $2,8 \pm 0,1 \mathrm{~b}$ & $25 \mathrm{a}$ \\
\hline LS & $1,7 \pm 0,1 \mathrm{a}$ & $9,0 \pm 1,2 \mathrm{a}$ & $3,1 \pm 0,3 \mathrm{a}$ & $10 \mathrm{~b}$ \\
\hline WPM & $1,5 \pm 0,1 \mathrm{~b}$ & $5,2 \pm 1,0 \mathrm{~b}$ & $1,9 \pm 0,5 \mathrm{~b}$ & $28 \mathrm{a}$ \\
\hline $\mathrm{CV}(\%)$ & 5,80 & 14,94 & 12,68 & 17,67 \\
\hline
\end{tabular}

${ }^{1}$ Médias seguidas pela mesma letra na coluna não diferem significativamente pelo teste de Scott-Knott $(\mathrm{p} \leq 0,05)$; Médias \pm desvio padrão.

A menor porcentagem de hiperidricidade foi observada durante o cultivo das brotações em meio de cultura LS, no qual $10 \%$ das brotações apresentaram-se hiperídricas. Para os demais meios de cultura comparados, a porcentagem de hiperidricidade foi superior e as taxas observadas foram 23-28\% (Tabela 2). O meio de cultura LS difere dos demais meios de cultura por ser adicionado $0,4 \mathrm{mg} \mathrm{L}^{-1}$ de tiamina- $\mathrm{HCl}$, sendo nos demais meios adicionado $0,2 \mathrm{mg} \mathrm{L}^{-1}$. Sintomas de hiperidricidade no cultivo in vitro de espécies de Lavandula já foram relatados em outros estudos (ANDRADE et al., 1999; TSURO et al., 2000; DIAS et al., 2002). Essa desordem do cultivo in vitro limita a micropropagação das plantas levando-as a morte na fase de aclimatização. Os resultados apresentados no presente estudo mostram que o meio de cultura é um fator relevante na eliminação do problema.

\section{Aclimatização}

Após a fase de multiplicação as microestacas foram enraizadas segundo MACHADO et al. (2011). Obteve-se $80 \%$ de sobrevivências das plantas de $\boldsymbol{L}$. angustifolia, após 30 dias de aclimatização. Deste resultado está de acordo com as taxas de sobrevivência obtidas anteriormente com plantas micropropagadas de espécies do gênero Lavandula. Para $\boldsymbol{L}$. viridis a sobrevivência foi de $80 \%$ durante a aclimatização (NOGUEIRA \& ROMANO, 2002). As plantas do híbrido lavandin, regeneradas a partir de folhas, foram aclimatizadas obtendo-se $100 \%$ de sobrevivência (DRONNE et al., 1999).

Após seis meses em casa-de-vegetação as plantas foram estabelecidas com sucesso a campo, apresentando $100 \%$ de estabelecimento.

Análise do óleo essencial

A produção do óleo essencial extraído das inflorescências de $\boldsymbol{L}$. angustifolia foi de 4,0\% e 5,25\% com base na massa seca, na primeira e segunda colheita, respectivamente. $\mathrm{O}$ teor encontrado nas duas colheitas está acima do encontrado para o óleo essencial de $\boldsymbol{L}$. angustifolia. $\mathrm{O}$ conteúdo do óleo essencial de $\boldsymbol{L}$. angustifolia cultivada na região sub-temperada de Kumaon, no oeste do Himalaia, foi 2,8\% (VERMA et al., 2010) e o conteúdo do óleo das inflorescências de diferentes acessos de lavanda coletadas em Kashmir variou de $0,80 \%$ a $1,3 \%$ (DHAR et al., 1982).

A composição e o teor dos componentes do óleo essencial de $\boldsymbol{L}$. angustifolia estão apresentados na tabela 3. No total foram identificados 18 - 21 constituintes, que correspondem a $93,13 \%$ na primeira colheita e 93,33\% na segunda colheita, do total do óleo. Nas duas colheitas realizadas os constituintes majoritários do óleo foram linalol (46,88\% e 37,25\%), acetato de linalila (10,09\% e 12,24\%), 1,8-Cineole + cis $\beta$ ocimeno $(7,63 \%$ e $10,64 \%)$ e acetato de lavandulila (6,98\% e 6,49\%) (Tabela 3). Na India o óleo essencial de $\boldsymbol{L}$. angustifolia apresentou maior teor de acetato de linalila $(47,56 \%)$ e, menor teor de linalol $(28,06 \%)$ (VERMA et al., 2010), comparados com os resultados encontrados no presente trabalho. Em estudo realizado na China o teor de linalol do óleo de $\boldsymbol{L}$. angustifolia foi de 44,54\% (CONG et al., 2008). As diferenças encontradas na composição e na quantidade dos constituintes em uma mesma espécie estão relacionadas à fatores genéticos e ambientais. Os monoterpenos e os sesquiterpenos apresentam-se como os compostos mais abundantes. A época de colheita e o horário também podem influenciar a composição e o teor do óleo (SILVA et al., 2007).

Na primeira colheita a porcentagem do constituinte borneol foi de $4,92 \%$ e o Nerol foi de $1,47 \%$. Já na segunda colheita os valores das porcentagens desses constituintes inverteram, sendo obtidos 1,22\% de borneol e 4,52\% de nerol (Tabela 3). O nerol é um composto oxigenado e juntamente com o acetato de geranila, são importantes para o aroma em geral do óleo, dando uma nota doce e agradável para o óleo. A cânfora, que deprecia o óleo de lavanda, não foi detectada no óleo essencial das inflorescências nas duas colheitas realizadas. 
Tabela 3 - Composição química do óleo essencial de inflorescências de L. angustifolia cv. 'Provence Blue', em dois anos de colheita em São Joaquim (SC).

\begin{tabular}{|c|c|c|c|c|c|c|}
\hline Constituintes & $\mathrm{IR}^{\mathrm{a}}$ & $\mathrm{IR}^{\mathrm{b}}$ & $\begin{array}{c}\text { Primeiro ano } \\
\text { Area (\%) }\end{array}$ & $\begin{array}{c}\text { Segundo ano } \\
\text { Area }(\%)\end{array}$ & $\operatorname{EP} 5^{\mathrm{c}}(\%)$ & ISO $3515^{\mathrm{d}}$ \\
\hline 3-Octanona & 983 & 979 & 1,08 & 1,20 & $0,10-2,5$ & $<2,0$ \\
\hline Mirceno & 987 & 988 & 0,58 & 1,33 & - & - \\
\hline Limoneno & 1028 & 1024 & 0,11 & - & - & - \\
\hline$\beta$-Felandreno & 1030 & 1025 & 0,51 & 0,63 & - & $<0,5$ \\
\hline 1,8 -Cineol+cis $\beta$ ocimeno & 1033 & 1026 & 7,63 & 10,64 & $<2,5$ & $<1,0$ \\
\hline Trans- $\beta$-ocimeno & 1043 & 1044 & 3,42 & 7,14 & - & - \\
\hline Oxido de linalol B & 1069 & 1067 & 0,41 & 0,18 & - & - \\
\hline Oxido de linalol A & 1086 & 1084 & 0,46 & 0,29 & - & - \\
\hline Linalol & 1098 & 1095 & 46,88 & 37,25 & $20-45$ & $25-38$ \\
\hline Acetato de 1-octen-3-ol & 1106 & 1110 & 0,52 & - & - & - \\
\hline Borneol & 1173 & 1165 & 4,92 & 1,22 & - & - \\
\hline$\sigma$-Terpineol & 1196 & 1199 & 1,87 & 1,90 & - & - \\
\hline Nerol & 1225 & 1227 & 1,47 & 4,53 & - & - \\
\hline Geraniol & 1249 & 1254 & 0,73 & 2,16 & - & - \\
\hline Acetato de linalila & 1251 & 1257 & 10,09 & 12,24 & $25-46$ & $25-45$ \\
\hline Acetato de lavandulila & 1281 & 1288 & 6,98 & 6,49 & $>0,2$ & $>2,0$ \\
\hline Nerolato etílico & 1357 & 1351 & 0,47 & 1,10 & - & - \\
\hline Acetato de geranila & 1376 & 1379 & 0,81 & 2,10 & - & - \\
\hline Trans-cariofileno & 1417 & 1417 & 3,98 & 2,64 & - & - \\
\hline Trans- $\beta$-farneseno & 1450 & 1454 & 0,20 & 0,29 & - & - \\
\hline Total Identificado & & & 93,12 & 93,33 & & \\
\hline
\end{tabular}

${ }^{a}$ Índices de retenção experimentais (coluna DB-5; referente a $n$-alcano); ${ }^{\mathrm{b}}$ Índices de retenção, literatura; ${ }^{\mathrm{c}}$ Farmacopéia Européia;

${ }^{\mathrm{d}}$ International Organization for Standardization (2002).

Acetato de lavandulila e 3-octanona foram encontrados dentro dos limites mencionados na EP 5 , e também na ISO 3515. Enquanto, as concentrações de linalol apresentaram-se acima dos limites estabelecidos (Tabela 3).

\section{CONCLUSÃO}

Para a micropropagação de $\boldsymbol{L}$. angustifolia cv. 'Provence blue' recomenda-se o meio de cultura LS acrescido de 1,0 $\mu \mathrm{M}$ BAP, por manter a qualidade das brotações na fase de multiplicação, com baixa taxa de hiperidricidade e não apresentar sintoma necrose apical das brotações.

As plantas micropropagadas de $\boldsymbol{L}$. angustifolia cv. 'Provence Blue' foram estabelecidas com sucesso em São Joaquim (SC), florescendo no verão.

O óleo essencial apresentou alto teor a partir da hidrodestilação das inflorescências, no primeiro e segundo ano de cultivo, apresentando como compostos majoritários o linalol e o acetato de linalila.

\section{REFERÊNCIAS}

ANDRADE, L. B. et al. The effect of growth regulators on shoot propagation and rooting of common lavender (Lavandula vera DC). Plant Cell, Tissue and Organ Culture, v. 56, $\mathrm{n}$. 02, p. 79-83, 1999.

BOPANA, N.; SAXENA, S. In vitro propagation of a high value medicinal plant: Asparagus racemosus Willd. In Vitro Cellular and Developmental Biology -Plant, v. 44, n. 06, p. 525532, 2008.

CALVO, M. C.; SEGURA, J. In vitro propagation of lavender. HortScience, v. 24, n. 02, p. 375-376, 1989.

CHISHTI, N. et al. Rapid in vitro clonal propagation of Lavandula officinalis Chaix: a multipurpose plant of industrial importance. Pakistan Journal of Biological Sciences, v. 09, n. 03, p. 514-518, 2006.

CONG, Y. et al. Chemical composition of the essential oil of Lavandula angustifolia from Xinjiang, China. Chemistry of Natural Compounds, v. 44, n. 06, p. 810, 2008.

DIAS, M. C. et al. Rapid clonal multiplication of Lavandula viridis L'Hér through in vitro axillary shoot proliferation. Plant Cell, Tissue and Organ Culture, v. 68, n. 01, p. 99-102, 2002. 
DRONNE, S. et al. A simple and efficient method for in vitro shoot regeneration from leaves of Lavendin (Lavandula $\mathrm{x}$ intermedia Emerck exloiseleur). Plant Cell Report, v. 18, n. 05, p. 429-433, 1999.

ECHEVERRIGARAY, S. et al. Micropropagation of Lavandula dentata from axillary buds of Field-grown adult plants. Biologia Plantarum, v. 49, n. 03, p. 439-442, 2005.

GEORGE, F. E. et al. Plant propagation by tissue culture. The Background. 3. ed., vol.1. 2008. 473 p.

HUSAIN, M. K.; ANIS, M. Rapid in vitro multiplication of Melia azedarach L. (a multipurpose woody tree), Acta Physiologiae Plantarum, v. 31, n. 04, p. 765-772, 2009.

JORDAN, A. M. et al. Micropropagation of adult Lavandula dentata plants. The Journal of Horticultural Science and Biotechnology, v. 73, n. 01, p. 93-96, 1998.

KINTZIOS, S. et al. The effects of light on callus growth and somatic embryogenesis from Lavandula vera and Teucrium chamaedrys: a preliminary study. Journal of Herbs, Spices \& Medicinal Plants, v. 09, n. 02, p. 223-227, 2002.

LINSMAIER, E. M.; SKOOG, F. Organic growth factors requeriments of tobacco tissue cultures. Physiologia Plantarum, v. 18, n. 01, p. 100-127, 1965.

LLOYD, G.; MCCOWN, B. Commercially-feasible micropropagation of mountain laurel, Kalmia latifolia, by use of shoot-tip culture. Proceeding International Plant Propagator's Society, v. 30, n. 03, p. 421-427, 1980.

MACHADO, M. P. et al. Enraizamento de microestacas de Lavandula angustifolia. Ciência Rural, v. 41, n. 05, p.767772, 2011. Disponível em: <http://dx.doi.org/10.1590/S010384782011000500005>. Acesso em: 15 out. 2011. doi: 10.1590/ S0103-84782011000500005.

MOON, T. et al. Antibacterial activity of essential oils, hydrosols and plant extracts from Australian grown Lavandula spp. The International Journal of Aromatherapy, v. 16, n. 01, p. 9$14,2006$.

MOUTET, L. Lavandin Abrialis, lavandin Grosso: what is their future? Perfum. Flavour, v. 4, p. 27-29, 1980.

MURASHIGE, T.; SKOOG, F. A. A revised medium for rapid growth and bioassays with tobacco tissue culture. Physiologia Plantarum, v. 15, n. 03, p. 473-497, 1962.

NOBRE, J. In vitro cloning and micropropagation of Lavandula stoechas from field-grown plants. Plant Cell, Tissue and Organ Culture, v. 46, n. 02, p. 151-155, 1996.
NOGUEIRA, J. M. F.; ROMANO, A. Essential oils from micropropagation plants of Lavandula viridis. Phytochemical Analysis, v. 13, n. 01, p. 4-7, 2002.

PANIZZA, M.; TOGNONI, F. Micropropagation of Lavandin (Lavandula officinalis Chaix x Lavandula latifolia Villars cv. 'Grosso'). In: BAJAJ, Y. P. S. Biotechnology in Agriculture and Forestry. New York: Spring. 1991. p. 295-305.

QUAZI, M. K. In vitro multiplication of Lavandula spp. Annals of Botany, v. 45, n. 03, p. 361-362, 1980.

RIBAS, L. L. F. et al. Micropropagação de Aspidosperma polyneuron (peroba rosa) a partir de segmentos nodais de mudas juvenis. Revista Árvore, v. 29, n. 04, p. 517-524, 2005.

SÁNCHEZ-GRAS, M. C.; CALVO, M. C. Micropropagation of Lavandula latifolia through nodal bud culture of mature plants. Plant Cell, Tissue and Organ Culture, v. 45, n. 03, p. 259-261, 1996

SILVA, F.; AZEVEDO, C. A. V. Anew version of the assistat statistical assistance software. In: World Congress on Computers in Agriculture, 4., Orlando-FL-USA. Anais... Orlando: American Society of Agricultural Engineers, 2006. p.393-396.

SILVA, L. C. et al. Meio nutritivo, reguladores de crescimento e frio no estabelecimento in vitro de mirtilo (Vaccinium ashei Reade) cv. 'Delite'. Revista Brasileira de Agrociência, v. 12 , n. 04 , p. 405-408, 2006.

SILVA, S.R.S. et al. Análise dos constituintes químicos e da atividade antimicrobiana do óleo essencial de Melaleuca alternifolia Chell. Revista Brasileira de Plantas Medicinais, v. 06, n. 01, p. 63-70, 2007.

SOARES, S.P. et al. Taxa de multiplicação e efeito residual de diferentes fontes de citocinina no cultivo in vitro de Hancornia speciosa Gomes. Ciência e Agrotecnologia, v. 35, n. 01, p. 152-157, 2011.

TSURO, M. et al. Efficient plant regeneration from multiple shoots formed in the leaf-derived callus of Lavandula vera, using the "open culture system". Scientia Horticulturae, v. 86, n. 01, p. $81-88,2000$.

VERMA, R.S. et al. Essential oil composition of Lavandula angustifolia Mill. cultivated in the mid hills of Uttarakhand, India. Journal of the Serbian Chemical Society, v. 75, n. 03 , p. $343-348,2010$

ZHANG, L. et al. Factors influencing shoot regeneration from cotyledons of tetraploid Isatis indigotica F. In Vitro Cellular \& Developmental Biology - Plant, v. 39, n. 05, p. 459-462, 2003.

ZUZARTE, M. R. et al. Trichomes, essential oils and in vitro propagation of Lavandula pedunculata (Lamiaceae). Industrial Crops and Products, v. 32, n. 03, p. 580-587, 2010. 